\title{
EL FONDO DE INFRAESTRUCTURA: ACIERTOS Y DUDAS FRENTE A SU FUNCIONAMIENTO
}

\author{
INFRASTRUCTURE FUND OF CHILE: \\ STRENGTHS AND DOUBTS \\ IN ITS OPERATION
}

\begin{tabular}{|c|c|}
\hline \multicolumn{2}{|c|}{ ARTÍCULO INÉDITO DE INVESTIGACIÓN } \\
\hline CÓMO CITAR ESTE ARTíCULO (CHICAGO) & $\begin{array}{l}\text { Kliwadenko Richaud, Alexander y Francisca } \\
\text { Ugalde Silva. «El fondo de infraestructura: } \\
\text { Aciertos y dudas frente a su funcionamiento». } \\
\text { Revista de Derecho Aplicado LLM UC } 7 \text { (2021). } \\
\text { https://doi.org/10.7764/rda.o.7.Ig633. }\end{array}$ \\
\hline REVISTA DE DERECHO APLICADO LLM UC & $\begin{array}{l}\text { Número } 7 \\
\text { Julio 202I } \\
\text { ISSN: } 245^{2-4344}\end{array}$ \\
\hline & $\begin{array}{l}\text { Recepción: } 23 \text { de agosto, } 2020 \\
\text { Aceptación: II de noviembre, } 2020\end{array}$ \\
\hline
\end{tabular}




\section{Resumen}

En 2018, mediante Ley 21.082, se ordenó la creación de una sociedad anónima del Estado denominada Fondo de Infraestructura S. A. Esta empresa pública tiene por fin desarrollar inversión pública y privada en materia de infraestructura y, a diferencia de otros fondos existentes a nivel mundial, que se centran en el financiamiento, en nuestro país este también tiene asignadas tareas respecto de la construcción, ampliación, reparación, conservación, explotación y desarrollo de proyectos de infraestructura. Este trabajo expone sus características, posibles beneficios y dudas sin resolver relativas a la normativa que dio origen a esta empresa pública.

Palabras clave: Desarrollo País, infraestructura, concesiones de obra pública, inversión pública.

\section{Abstract}

In 2018, by mandate of the Law 21,082, the Chilean Fund of Infrastructure, now called "Desarrollo País", was created. The purpose of this public company is the development of public infrastructure, not only by providing the necessary funds - like is the case with similar enterprises around the world but also by directly constructing, expanding and exploiting the national infrastructure. We analyze its characteristics, benefits and the doubts remaining regarding its current regulation.

Keywords: Desarrollo País, infrastructure, public work concessions, public investment. 


\section{Alexander Kliwadenko Richaud}

Ibarra \& Asociados

Santiago, Chile

akr@ibarraasociados.cl

Ibarra \& Asociados

Santiago, Chile

akr@ibarraasociados.cl
Licenciado en Ciencias Jurídicas y Sociales de la Universidad Diego Portales, Chile. LLM en Competition Law del King's College London, Reino Unido. Global Competitive Leadership Program, McDonough Business School de la Universidad de Georgetown, Estados Unidos, en 2014. Socio del estudio Ibarra \& Asociados. Su práctica profesional se ha centrado en materias de obras públicas y derecho económico.

Bachelor of Laws (LL.B.), Diego Portales University of Chile School of Law. LL.M. in Competition Law from the King's College in London, United Kingdom (2017-2018), and a Global Competitive Leadership Program in Georgetown University, Washington D. C., United States (2013- 2014). Worked as Prosecutor and Head of the Legal Division of the MOP Public Works Franchise and Concession Coordination from 2014 to 2017. He has a longstanding experience in infrastructure, state concession contracts and economic law. Partner of the lawfirm lbarra \& Asociados.

\section{Francisca Ugalde Silva}

Ibarra \& Asociados

Santiago, Chile

fus@ibarraasociados.cl

Ibarra \& Asociados

Santiago, Chile

fus@ibarraasociados.cl
Abogada. Licenciada en Ciencias Jurídicas de la Pontificia Universidad Católica de Chile. Candidata a Magíster en Derecho Regulatorio de la misma casa de estudios. Diploma de postítulo en Regulación y Derecho Público de la Universidad de Chile. Su práctica profesional se ha centrado en materias de contratación pública y mercados regulados.

Bachelor of Laws (LL.B.), Pontifical Catholic University of Chile. LL.M. Candidate Masters in Regulatory Law, Pontifical Catholic University of Chile. Postgraduate diploma in Regulation and Public Law, University of Chile. Her practice has centered in public procurement and regulated markets. 


\section{INTRODUCCIÓN}

A partir del año 2013, debido a diversos factores - entre los cuales destacan una brecha significativa en infraestructura acumulada por años y una creciente estrechez presupuestaria para inversión en obras públicas, ${ }^{1}$ así como dificultades en crear una agenda de obras públicas con perspectiva de largo plazo-, la inversión pública y privada en infraestructura fue decayendo en forma progresiva. Esto impulsó a algunas instituciones privadas, como el Consejo de Políticas de Infraestructura (CPI) y la Cámara Chilena de la Construcción, así como al propio Ministerio de Obras Públicas, a proponer diversas alternativas para aumentar la inversión en esta materia, entre las que destacan la creación de un fondo que permitiera rentabilizar los activos que el Estado había desarrollado mediante el mecanismo de las concesiones de obras pública.

De este modo, a mediados del 2014, el Gobierno de la entonces presidenta Michelle Bachelet anunció la «Agenda de Infraestructura, desarrollo e inclusión, Chile 30.30». Esta contemplaba, entre otras cosas, la optimización del sistema de concesiones, con el objeto generar la infraestructura necesaria para favorecer que Chile, al año 2030, sea un país de USD 30.000 per cápita, para lo cual se creyó indispensable reforzar la institucionalidad en obras públicas, a fin de otorgarle más solidez y transparencia. ${ }^{3}$ Lo anterior, considerando, además, que en un principio el sistema de concesiones fue ideado para el desarrollo de proyectos viales; no obstante, con el tiempo se fue utilizando en otros proyectos de mayor complejidad, como cárceles, edificios públicos y hospitales, lo que hizo urgente una actualización de su institucionalidad.

De este modo, el desafío se abordaría por dos vías distintas:

- Mediante la transformación de la Coordinación de Concesiones de Obras Públicas - jerárquicamente bajo el mandato de la Dirección General de Obras Públicas - en una Dirección General de Concesiones de Obras Públicas, con director propio y mayores potestades para resolver.

1 Según el Ministerio de Obras Públicas, la inversión en obras públicas había disminuido en forma significativa desde 2006 a 20I4. «Mandataria presentó el "Plan de Infraestructura, Desarrollo e Inclusión” del MOP», Ministerio de Obras Públicas, 3 de agosto de 20I 4 , http://www. vialidad.cl/noticias/Paginas/DetalledeNoticias.aspx?item $=506$.

2 El Consejo de Políticas de Infraestructura es una institución privada que agrupa a exautoridades, académicos y representantes de gremios vinculados a la infraestructura con el objetivo de proponer políticas de largo plazo. El Consejo planteó la idea de constituir dicho fondo de infraestructura a partir de los excedentes de los peajes.

3 Como señala el mensaje del proyecto de la Ley 21.082. 
- Estableciendo una nueva institución o mecanismo que permitiese el traspaso de flujos financieros que generan algunos activos del sistema de concesiones a otros proyectos de infraestructura. Así, surgió con fuerza la idea de crear un Fondo de Infraestructura (o Desarrollo País), lo que llevó a ingresar al Congreso un proyecto de ley al respecto en mayo de 2016.

La idea central de este fondo era poder contar con una institución independiente de la Administración y del Fisco, para la utilización de los recursos obtenidos del valor residual ${ }^{4}$ de las concesiones, que se refiere a los recursos que se generan al momento de expirar la vigencia de una concesión de obra pública, cuya inversión ya ha sido recuperada y que luego será nuevamente licitada o «relicitada». En otras palabras, se trata del valor que tiene una autopista al término de una concesión, mediante la cual se ha financiado la inversión en esa obra. Esto, por mandato legal, una vez concluido el plazo de la concesión, el Estado deberá volver a licitar esa autopista ${ }^{5}$, a diferencia de la primera concesión —en que la obra no existía-, esta vez no será necesario crear la infraestructura. Si la nueva concesión conserva la misma tarifa de peaje que la anterior - o una similar-, entonces existe un valor económico asociado a relicitar la concesión, al cual se denomina valor residual. La idea entonces es asegurar que ese valor o recursos ${ }^{6}$ no sean asignados a otras tareas fiscales, sino que se destinen a la generación de nueva infraestructura para el país.

En consecuencia, en enero del 2018 se aprobó por el Congreso Nacional la Ley 21.082, publicada el 24 de marzo de 2018, que ordenó la creación de la sociedad anónima del Estado denominada Fondo de Infraestructura S. A.

4 El valor residual es el valor que tiene un bien inmueble al final de su vida útil, una vez deducidos los gastos por amortización y depreciación. Desde otro punto de vista, el valor residual es el importe que la empresa espera obtener al vender el bien cuando finalice su vida útil. Como señala González, «si una nueva concesión mantiene la misma tarifa de peaje que la primera, entonces existe un valor económico asociado a relicitar la concesión, al cual denominamos valor residual». Aldo González, «El fondo de infraestructura de Chile», Estudios de Políticas Públicas $4, \mathrm{n}^{\circ}{ }_{2}(20 \mathrm{I} 8), \mathrm{I}_{7} 6$.

5 Salvo que el presidente de la República disponga algo distinto, como señala el artículo 25 de la Ley de Concesiones de Obras Públicas.

6 «Normalmente, el valor residual se materializaría al momento de realizar la licitación. En nuestro caso simplificado, por ejemplo, al adjudicarse la operación y mantención de la obra en base a quién pague más al Estado por obtener la concesión. Puede ser un pago fijo al momento de traspasar la concesión o bien una serie de pagos anuales durante el período del contrato con el nuevo concesionario». González, «Fondo», I76. 
En términos generales, se constituyó como una empresa autónoma, con patrimonio propio, y gobierno corporativo separado de la Administración del Estado. Es decir, se optó por sujetar esta entidad al estatuto jurídico aplicable a las sociedades anónimas abiertas, sometiéndola, además, a la fiscalización de la Contraloría General de la República, en los términos del inciso segundo del artículo 16 de la Ley 10.336.

La Ley encomienda al Fondo un rol activo en actividades empresariales de inversión y desarrollo de proyectos de infraestructura. En concreto, el artículo 4 establece dos tareas esenciales:

- Financiar o invertir en proyectos de infraestructura, tanto de forma directa como a través de terceros, incluyendo, además, la elaboración y ejecución de los estudios que resulten necesarios.

- Construir, ampliar, reparar, conservar, explotar y desarrollar dichos proyectos de infraestructura, lo que únicamente podrá hacerse a través de terceros no relacionados.

Junto con ello, existen también otras labores encomendadas, como: i) realizar gastos o inversiones de carácter físico o financiero para nuevos proyectos, fomentando su construcción y desarrollo, en la forma en que determine el directorio, velando por mantener la solvencia de la empresa; ii) emitir instrumentos financieros de deuda, garantías u otros autorizados expresamente por el directorio; iii) constituir sociedades anónimas filiales o coligadas para cumplir su objeto, previa autorización de la junta de accionistas y, iv) en general, ejecutar todos los actos tendientes a cumplir con lo anterior, incluyendo las demás actividades que expresamente se establezcan en la Ley.

En el ejercicio de las actividades mencionadas, el Fondo debe tomar todas las precauciones que sean necesarias para conseguir:

- La sostenibilidad financiera de la cartera de proyectos.

- La obtención de utilidades anuales en cada ejercicio.

Respecto de su constitución formal, la Ley establece que sus accionistas serán el Fisco y Corfo, quienes, en el plazo de seis meses desde la entrada en vigor de la Ley, constituirían una sociedad anónima denominada Fondo de Infraestructura S. A., lo que ocurrió el 24 de septiembre de 2018. ${ }^{7}$ Más adelante, el 22 de enero de 2020, se reformaron los

$7 \quad$ En esa fecha se suscribió la escritura pública ante el notario Iván Torrealba, mientras que el 4 de octubre de 2018 fue inscrito el extracto de escritura pública de constitución a fojas $75 \cdot 5$ Io número $3^{8.768}$ del año 20I8, del Registro de Comercio del Conservador de Bienes Raíces de Santiago, y publicado en el Diario Oficial el 3 r de octubre de 2018. 
estatutos sociales ${ }^{8}$ y se decidió utilizar el nombre de fantasía Desarrollo País, junto con agregar una serie de otras modificaciones respecto del funcionamiento de la sociedad anónima.

Pues bien, el hecho de que el Fondo todavía no haya ejecutado ninguna obra, así como una serie de ambigüedades presentes en la Ley, han abierto diversas interrogantes que consideramos es necesario esclarecer, con mayor apremio en estos momentos, cuando se busca utilizar la inversión en infraestructura pública para reactivar la economía y crear puestos de trabajo, golpeados por los efectos de la pandemia de la enfermedad covid-19.

Este trabajo, primero, expondrá la regulación del Fondo de Infraestructura S. A., sus objetivos, funcionamiento y limitaciones; desarrollará algunos de los aspectos de la Ley que, creemos, cuentan con algunas imprecisiones, así como abordará algunas interrogantes respecto de su posible rol en el sistema chileno de infraestructura, bajo el entendido de que se trata de una institución que ha entrado en funcionamiento en forma muy reciente y, por tanto, su rol es todavía incierto. Por último, se expondrán alguno de los riesgos que creemos se pueden presentar una vez que comience a intervenir ya directamente, así como se entregarán algunas propuestas que, consideramos, pueden mitigarlos.

\section{FONDO DE INFRAESTRUCTURA S. A.}

\section{I. ¿Qué son los fondos de infraestructura?}

Los fondos de infraestructura son instituciones cuya principal tarea es aumentar la inversión pública y privada en materia de infraestructura pública, para lo cual se dotan con distintas atribuciones y mecanismos mediante los cuales se busca superar los problemas asociados a la falta de financiamiento a largo plazo para estas obras, generando con ello incentivos para la inversión desde el mundo privado.

Instituciones como estas se encuentran en diversos ordenamientos jurídicos alrededor del mundo. Algunos ejemplos, junto al detalle de su organización, son:

- Infrastructure Finance Unit, Reino Unido: Creado en 2009 dentro de la Tesorería del Reino Unido luego de la crisis financiera del año 2008, tiene el

8 El acta fue reducida a escritura pública el 29 de enero de 2020 en la notaría de Santiago Benavente Cash; el extracto de dicha escritura pública fue inscrito a fojas Io.759 número 5.66r del año 2020, del Registro de Comercio de Santiago y publicado en el Diario Oficial el Io de febrero de 2020 . 
objetivo de otorgar financiamiento a proyectos de asociación pública-privada, ${ }^{9}$ que puede darse solo o en conjunto con la banca privada y el Banco Europeo de Inversión. Se señala que, aunque esta unidad es un organismo público, opera en la práctica como un banco, otorgando préstamos y créditos tal como lo harían esas instituciones. ${ }^{10}$

- Transportation Infrastructure Finance and Innovation Act, Estados Unidos: Es un programa a nivel federal que maneja el Departamento de Transportes, cuyo objeto es entregar asistencia crediticia para proyectos como carreteras, sistemas de transporte ferroviarios, puertos y otros, con la idea de introducir inversión privada y no federal para estimular nuevas inversiones en dicha infraestructura. ${ }^{11}$

- Fondo de Inversión en Infraestructura (BIIF), Brasil: Se trata de un fondo de inversión mixto dedicado principalmente a otorgar financiamiento a proyectos de infraestructura pública, como transporte, energía, tratamiento de aguas, etcétera. ${ }^{12}$

- Infrastructure Ontario, Canadá: Se trata de una corporación de la Corona, cuya tarea es apoyar a los gobiernos provinciales en la construcción de infraestructura, ya sea mediante el otorgamiento de financiamiento vía créditos,

9 No existe una definición única de asociación público-privada (APP), ni tampoco están definidas en nuestro ordenamiento, pero, «en líneas generales, una asociación público-privada se refiere a un acuerdo entre el sector público y el sector privado en el que parte de los servicios o labores que son responsabilidad del sector público es suministrada por el sector privado bajo un claro acuerdo de objetivos compartidos para el abastecimiento del servicio público o de la infraestructura pública». «乙Qué son las asociaciones público-privadas?», Banco Mundial, I de febrero de $20 \mathrm{I} 7$, https://ppp.worldbank.org/public-private-partnership/es/asociaciones-publico-privadas/definicion.

10 Ed Farquharson y Javier Encinas, «The UK Treasury Infraestructure Finance Unit: Supporting PPP Financing During the Global Liquidity Crisis», Public-Private Partnership Solutions, Banco Mundial, http://siteresources.worldbank.org/WBI/Resources/2I3798-I2590II53I325/ 6598384-I268250365374/PPP_Solutions_or.pdf.

11 «Transportation Infrastructure Finance and Innovation Act (TIFIA)», U.S. Department of Transportation, Federal Highway Administration, https://www.fhwa.dot.gov/fastact/ factsheets/tifiafs.cfm.

12 «BR-Lion: Infraestructura Fondo de Inversión Brasil (BIIF)», Banco Interamericano de Desarrollo, https://www.iadb.org/es/project/br-lioII. 
o mediante la administración de los bienes públicos y fiscales, ${ }^{13}$ a través de contratos de asociación público-privada.

Además, encontramos otras modalidades de fondos, como es el caso del fondo para el cierre de brechas financieras de India (Viability Gap Fund); el Fondo Margarita de la Unión Europea, el Fondo Nacional de Infraestructura de México y varios más.

Se puede observar, entonces, que se trata de una figura usada en distintas latitudes y ordenamientos jurídicos, en general dedicados a entregar financiamiento a proyectos de interés público, ya sean organismos estatales o privados, a modo de suplir la falta de presupuesto público, así como dificultades de acceso a crédito por parte de distintas empresas. Entre ellos, creemos que Infrastructure Ontario es más similar a Desarrollo País, pues no se dedica solamente al financiamiento, sino que también interviene en la construcción y administración de infraestructura pública.

\section{2. ¿Por qué un fondo de infraestructura en Chile?}

Como se señaló, el principal propósito detrás de Desarrollo País fue aumentar la inversión tanto pública como privada en el ámbito de la infraestructura pública.

Dada la escasez presupuestaria para alcanzar ese objetivo, con su creación se pretende traer al presente el valor residual de las concesiones, que, como se explicó, es aquel que se genera al momento de expirar los contratos de las obras públicas en operación. En ese sentido, la Ley autoriza al Fondo para que, una vez terminada la vigencia de una concesión, esta pueda ser relicitada, manteniendo, disminuyendo o aumentando los bienes y derechos comprendidos en ella. De este modo, la adjudicación de la operación y mantención de la obra se puede determinar en base al oferente que esté dispuesto a pagar más al Estado por hacerse de aquella concesión. Esto se puede lograr mediante un monto fijo que se entrega al Estado al momento del traspaso de la concesión, o bien, puede tratarse de una serie de pagos anuales durante toda la vigencia del nuevo contrato.

Pero eso no es todo, ya que un fondo puede también retener parte del valor que se obtiene de una obra al cobrar un peaje, cuya tarifa está por sobre el costo medio de largo plazo de la obra de infraestructura. Es decir, obtener ganancias en aquellas obras en donde ya existe infraestructura y cuya recaudación supera los gastos de operación y mantención necesarios para cumplir con los niveles de servicios establecidos en dicho contrato de concesión.

13 «Partnering to Modernize Ontario's Public Assets», Infrastructure Ontario, https://www.infrastructureontario.ca/Real-Estate-Services/. 
Ahora bien, como veremos, actualmente se plantea, además de las concesiones, utilizar mediante este Fondo bienes públicos desaprovechados, como terrenos fiscales baldíos o abandonados. Así, el directorio de la empresa ha propuesto que estos le sean traspasados, a fin de valorizar esos bienes y desarrollar distintos tipos de proyectos. ${ }^{14}$

\section{3. ¿Cuáles son las tareas que deberá desempeñar este fondo en Chile?}

En cuanto al objetivo principal de esta empresa, es decir, conseguir la mayor inversión en infraestructura anhelada para el país, la Ley establece que el Fondo deberá centrarse en llevar a cabo una serie de labores, las cuales, a rasgos generales, son las siguientes:

- Fomentar iniciativas de APP bajo el modelo de concesiones $u$ otros que impliquen la presencia del sector privado.

- Participar en la evaluación y estructuración financiera de proyectos de infraestructura productiva o social, que cuenten con participación privada y tengan una rentabilidad económica o social positiva, según las disposiciones y procedimientos aplicables.

- Generar y administrar instrumentos financieros asociados a proyectos de infraestructura, para que estos se conviertan en bancables mediante condiciones competitivas de largo plazo.

- Otorgar aportes no recuperables a proyectos rentables socialmente, siempre que cuenten con participación privada para su implementación y formen parte de la cartera de proyectos prioritaria para el país y sus regiones, definida por las autoridades pertinentes.

- Disponer y rentabilizar, según lo determinen las reglas de inversión fijadas por su directorio, los activos que configuren su patrimonio.

- Apoyar la ejecución de estudios e investigaciones relacionados con áreas o proyectos de infraestructura prioritarios para el país.

14 «Desarrollo País», Desarrollo País, 30 de junio de 2020, https://desarrollopais.cl/desarro1lo-pais/. 
Ahora bien, se deben tener siempre presente dos elementos esenciales y orientadores del actuar del Fondo de Infraestructura chileno:

- Como señala el artículo 4 de la Ley, el Fondo debe constituirse en una empresa rentable y sostenible en el tiempo, lo que no necesariamente significa que por ello pueda desconocer el rol o función pública que le corresponde.

- La Ley ha sido enfática en señalar - como indica su artículo 5-que, para la construcción, ampliación, reparación, conservación, explotación y desarrollo de proyectos de infraestructura, el Fondo solamente puede actuar a través de terceros no relacionados con este. Es decir, las obras públicas solo podrán ser ejecutadas por medio de privados (que debiera ser la regla general), o bien, bajo otras modalidades contractuales cuando la naturaleza del proyecto así lo justifique.

A su vez, la Ley, en su artículo 5, inciso tercero, autoriza al Fondo para celebrar convenios con el Ministerio de Obras Públicas (MOP), para que este último, actuando como representante del primero, otorgue nuevas concesiones a terceros..$^{15}$ Además, el MOP puede acordar con otras entidades públicas convenios destinados a contar con apoyo técnico para la estructuración, asignación y ejecución de dichos contratos.

Sea cual sea la modalidad contractual escogida por el Fondo, esta deberá ser asignada por medio de una licitación pública, que garantice condiciones de competencia e igualdad entre los participantes, así como los principios de transparencia y estricta sujeción a las bases. En ese sentido, como dispone el artículo 23 de la Ley, el Fondo está llamado a ser un garante de la competencia en el mercado de la infraestructura pública, por lo que es posible que deba sostener un diálogo permanente con la Fiscalía Nacional Económica, y, eventualmente, con el Tribunal de Defensa de la Libre Competencia. Precisamente, el gerente de Desarrollo País declaró en su sitio web, el 6 de abril de 2020, que busca tener «neutralidad competitiva», buscando entrar en «espacios en que, ya sea por falta de garantía o de historia, los privados no entran [...] la idea no es competir con los privados dando financiamiento de un banco, eso ya está resuelto por el mercado». ${ }^{16} \mathrm{~A}$ pesar de ello, veremos en la última sección que existen dudas sobre este aspecto del funcionamiento del Fondo.

15 Cabe señalar que, para evitar problemas de duplicidades, los mandatos que conceda el Fondo al MOP deberán cumplir exhaustivamente con la exigencia de establecer en forma detallada todos los términos de dicho mandato, los aspectos que sean necesarios para el desarrollo del proceso de licitación que otorgue una concesión a terceros y la definición de aplicación total o parcial del estatuto jurídico de concesiones de obras públicas.

16 «El Fondo de Infraestructura tendrá "neutralidad competitiva" con los privados», Desarrollo País, 6 de abril de 2020, https://desarrollopais.cl/fondo-de-infraestructura-queda-listo-para-ser-ley-copy/. 
Por último, no se debe olvidar que el Fondo fue creado principalmente para cumplir un rol financiero, centrado en generar instrumentos que, a partir del valor de la infraestructura concesionada o de bienes fiscales, puedan generar las condiciones para la inversión en proyectos cuyas particularidades los vuelven más complejos.

Según el plan quinquenal aprobado en mayo de 2020, los proyectos que se busca priorizar son edificios habitacionales ligados al subsidio de arriendo protegido, a partir de terrenos fiscales que le sean aportados; desarrollo de infraestructura de servicio en barrios cívicos; inversiones en fibra óptica; construcción de plantas desaladoras para el uso en agricultura; y dar uso comercial a terminales de buses de la red de transporte de Santiago, según se publicó en el sitio web de Desarrollo País el 20 de junio de 2020. ${ }^{17}$

\section{4. ¿Cómo se administra este fondo?}

Resulta de suma importancia para cualquier empresa pública conocer la manera en que se administra. Pues bien, como se indica en el artículo 2 de la Ley, el Fisco y la Corfo, en conformidad con su ley orgánica, el 24 de septiembre de 2018 constituyeron la sociedad Fondo de Infraestructura S. A., que se rige por las normas de la Ley 18.046 sobre sociedades anónimas abiertas, junto con aquellas contenidas en la Ley que le da existencia. Como señala el artículo 15, la administración del Fondo es ejercida por un directorio compuesto por cinco miembros, que son designados por el presidente de la República según requisitos establecidos en la ley; en su mayoría, se trata de profesionales con reconocido prestigio en el rubro. Cabe agregar que la Ley establece ciertas prohibiciones y obligaciones para los directores que cesen en sus funciones por alguna de las causales del artículo 19 de la Ley, aplicándoseles, en caso de contravención, multas de hasta 500 unidades tributarias mensuales.

El directorio debe elaborar un plan de negocios quinquenal, el cual debe contener - entre otros elementos- los objetivos y metas de rentabilidad del Fondo, los planes de inversión y desarrollo, la política y necesidad de endeudamiento, y el programa de disposición de activos y de unidades de negocios no esenciales (artículo 25 de la Ley). Se trata en la práctica de una «hoja de ruta» que deberá ser puesta en conocimiento del MOP para que emita un informe técnico, y luego deberá ser presentado a la junta de accionistas para su aprobación o rechazo. Como mencionamos, ya existen planes aprobados, el último mediante junta de accionistas del 26 de mayo de 2020.

17 «Empresa estatal Desarrollo País revela plan quinquenal por hasta US\$ I.375 mills.», Desarrollo País, 20 de junio de 2020 , https://desarrollopais.cl/empresa-estatal-desarrollo-pais-revela-plan-quinquenal-por-hasta-us-I-375-mills/. 
En caso de que el plan contemple operaciones que impliquen requerimientos de aportes fiscales, se debe cumplir antes con el procedimiento que establece la Ley en su artículo 23 - en el caso de que el directorio acuerde financiar o invertir en proyectos de infraestructura que puedan requerir aporte fiscal, se deberá cumplir con los requisitos y procedimientos que están contenidos en esa norma- y contar además con la autorización del Ministerio de Hacienda mediante un informe técnico.

Es importante que el directorio tenga siempre en consideración que su objetivo principal es constituirse en una empresa rentable y sostenible en el tiempo, pero también, el rol o función pública que le concierne. Se trata de dos objetivos que, creemos, sin duda van a generar tensiones internas, en especial al momento de definir su participación (o no) en algunos proyectos.

\section{5. ¿Cuál es el capital y patrimonio del Fondo?}

Por otra parte, para poder cumplir con sus objetivos, esta empresa necesitará de capital; el artículo 11 de la Ley señala que el Fondo estará constituido por:

- El aporte que realicen el Fisco y la Corfo, en proporción a la participación accionaria de cada uno. En particular, el Fisco «podrá suscribir y pagar el capital inicial, total o parcialmente, con el aporte de bienes fiscales y nacionales de uso público, valorados económicamente». ${ }^{18}$

- Las utilidades que obtenga en el desarrollo de sus actividades financieras comerciales, cuya capitalización haya sido autorizada por la junta de accionistas.

Ahora bien, respecto de ese aporte inicial del Fisco y Corfo, se debe indicar que no existe mayor claridad sobre bajo qué figura jurídica en específico los «bienes nacionales y de uso público» quedarán bajo el alero del Fondo. ${ }^{19}$ Esta es una de las mayores imprecisiones que, a nuestro entendimiento, presenta la Ley en su actual redacción.

Nos referimos a cómo ingresarían al patrimonio de una sociedad que se rige por el derecho civil bienes que, conforme al artículo 19 numeral 23. ${ }^{\circ}$ de la Constitución Política, no tienen dueño y pertenecen a la nación toda. Es decir, bienes que por su naturaleza

18 Según la constitución de la sociedad, el Fisco suscribió 6.435 acciones por un valor de CLP 6.435 millones, mientras que Corfo suscribió $6_{5}$ acciones por un valor de CLP $6_{5}$ millones. Se señala que se pagará ese capital inicial «en aporte de recursos o activos financieros».

19 Sobre este tema, ver Alicia de la Cruz, «Fondo de infraestructura: Las dudas frente a inconsistencias de derecho público», Cuadernos de Extensión Jurídica de la Universidad de los Andes $3^{\mathrm{I}}$ (20I8): I35-I 43 . 
son inapropiables e inalienables. Es de toda lógica preguntarse cómo se van a poder embargar estos bienes que ni siquiera están inscritos en el Conservador de Bienes Raíces; cómo se valorizarán esos bienes y bajo qué figura jurídica ingresarán al patrimonio del Fondo, y qué es lo que se transfiere de ellos: zse trata del dominio o tan solo su uso y goce (administración) $2^{20}$

Creemos que, al menos tratándose de los bienes nacionales de uso público, al ser inalienables, imprescriptibles, y por lo general no susceptibles de apropiación, la única vía jurídicamente aceptable para que el Estado pudiera aportarlos al patrimonio del Fondo sería traspasando su administración, para que el Fondo tenga su tuición y conservación, siempre tomando en consideración el interés público. ${ }^{21}$ Una situación distinta sería respecto de los bienes fiscales, que están sujetos a la regulación del derecho civil y, por tanto, sí pueden ser aportados en propiedad por el Fisco, siguiendo para ello lo dispuesto en el Decreto Ley 1.939 de 1977.

Cabe señalar que el artículo segundo transitorio de la Ley se refiere únicamente a las rutas y carreteras, las que traspasa al patrimonio, autorizando su explotación una vez pagada la concesión, vía tarifa. Sin embargo, dado el espíritu del proyecto y la propia historia de la ley, parece lógico que dichos conceptos deben ser entendidos en un sentido más amplio, es decir, que no se limiten solo a obras camineras o carreteras, sino que incorporen obras como las portuarias, de ferrocarriles, cables de telecomunicación y embalses de uso múltiple, etcétera, lo que, como vimos, ha sido avalado por las declaraciones del directorio de Desarrollo País en los últimos meses. En definitiva, estas dos interpretaciones son las que consideramos las únicas posibles para solucionar estas ambigüedades que presenta la norma.

En cuanto a la relación con el Fisco, la Ley es clara al señalar en su artículo 27 que el Fondo no podrá obtener créditos, fianzas o garantías del Estado o de cualquiera de sus organismos, entidades o empresas, mientras que el artículo 28 establece que la Ley de

20 Es importante señalar que, en la discusión parlamentaria, se habló de que los bienes nacionales de uso público se entregarían al Fondo para su administración. Senado de Chile, «Primer informe de la Comisión de Obras Públicas», Biblioteca del Congreso Nacional, historia de la ley 2г.082, https://www.bcn.cl/historiadelaley/nc/historia-de-la-ley/7523/.

21 En 20I9 se estudiaba modificar la Ley para especificar que estos bienes serían entregados en concesión al Fondo, según informó Carla Cabello en un artículo en Pulso de La Tercera el $2_{4}$ de septiembre de 2019 , pero hasta el momento de redactar este trabajo no existe ninguna iniciativa concreta al respecto. Carla Cabello, «Los cinco aspectos que el Gobierno definió ajustar en la ley que creó el Fondo de Infraestructura», La Tercera, $2_{4}$ de septiembre de 20I9, https://www.latercera.com/pulso/noticia/los-cinco-aspectos-gobierno-definio-ajustar-la-ley-creo-fondo-infraestructura/83209/. 
Presupuestos del Sector Público podrá contemplar transferencias de capital para proyectos específicos del Fondo, bajo ciertos requisitos. ${ }^{22}$ Por tanto, es evidente que existirá una relación permanente entre el Fondo y el Estado, en cuanto cada año deberá determinarse la posibilidad de transferir a este organismo parte del presupuesto nacional para entregar aumentos de capital que le permitan desarrollar proyectos.

Como vimos, los activos del Fondo estarían compuestos principalmente por bienes y derechos de los contratos de concesiones de Obras Públicas (traspasados al mismo), ${ }^{23}$ es decir, por el valor económico presente de los bienes concesionados, así como distintos bienes fiscales. Dicho valor se determina por el excedente de flujos futuros de las concesiones por relicitar, más el valor residual o de infraestructura preexistente, al momento de la nueva licitación. Junto con ello, existirán los eventuales aportes de coparticipación hechos por entidades financieras multilaterales, así como los intereses, comisiones y reajustes por concepto de operaciones financieras hechas con los vehículos de los proyectos, y los demás recursos y derechos que obtenga por cualquier concepto, para el cumplimiento de sus objetivos.

Por último, debe indicarse que la Ley no contempla normas concretas acerca de políticas de reinversión de utilidades, de manera de que estas se destinen efectivamente a la explotación del giro del Fondo, y no a financiar otro tipo de políticas públicas. Este es un punto que podría incluirse dentro de una posible reforma legal, de considerarse necesario.

\section{6. ¿Cuál es el marco legal que rige al Fondo?}

En esta sección exploraremos las normas, además de la Ley 21.082, que regulan el funcionamiento de esta empresa. La primera norma aplicable, evidentemente, es el artículo 19 numeral $21^{\circ}$ de la Constitución Política, en cuanto el Fondo es una empresa pública y, por tanto, como señala dicha norma, sus actividades están sujetas a la legislación común aplicable a los particulares, salvo lo que la ley respectiva, justificadamente, excepcione.

22 a) Que se haya dado cumplimiento al procedimiento señalado en el artículo 23; b) que el proyecto se encuentre incluido en el plan de negocios quinquenal aprobado por la junta de accionistas, de acuerdo con lo indicado en el artículo 25; c) que el proyecto se encuentre evaluado y recomendado por el Ministerio de Desarrollo Social, según su normativa y a lo señalado en el artículo ig bis del Decreto Ley I.263, del Ministerio de Hacienda, de I975, orgánico de administración financiera del Estado; d) que el proyecto se encuentre debidamente identificado, previo a su ejecución, de acuerdo con lo prescrito en el artículo 26; y e) que el monto máximo de las transferencias al proyecto, en el periodo que dure la concesión respectiva, no exceda al monto necesario para que el Fondo registre variaciones patrimoniales por efecto de la ejecución del proyecto beneficiado.

23 Se esperaba que la primera obra en ingresar fuera la concesión de la ruta Talca-Chillán, pero finalmente esta se está relicitando por el MOP. 
En caso de que el Fondo adjudique una concesión, el artículo 5 de la Ley establece que debe utilizar el estatuto fijado por el Decreto Supremo 900 del Ministerio de Obras Públicas de 1996 (Ley de Concesiones), y su reglamento. No obstante, añade que «excepcionalmente y para proyectos determinados», el Fondo podrá utilizar otro estatuto concesional o modalidad de contratación, ${ }^{24}$ aunque no establece parámetros que permitan determinar, de forma previa, qué proyectos calificarían. Para dichos casos excepcionales, la Ley señala que la modalidad de contratación y el procedimiento de licitación pública deberán ser autorizados por la junta de accionistas, en los términos del artículo 25, el cual regula el plan de negocios quinquenal. Es decir, cada procedimiento concursal deberá ser estudiado para determinar cuál procedimiento de contratación se podría utilizar, que podría ser - por ejemplo- la Ley 19.886, sobre contratos de suministros y prestación de servicios.

En complemento de lo anterior, es importante mencionar que no todas las normas de la Ley de Concesiones resultarán aplicables a dichos contratos, dado que la Ley indica que le serán aplicables las normas de los capítulos 3 a 11, ambos inclusive, excluyendo además algunos artículos específicos contenidos en esos capítulos. ${ }^{25}$

En cuanto a posibles modificaciones del contrato, el artículo 7 de la Ley permite al Fondo y al concesionario acordar «las adecuaciones a los contratos de concesión que resulten imprescindibles, a objeto de incrementar los niveles de servicio y estándares técnicos establecidos en las bases de licitación, velando siempre por mantener o incrementar el valor económico del Fondo». El tenor es claro en establecer la relación causal que debe existir entre la modificación del contrato y su objeto, que no es otro que la incrementación de los niveles de servicio y estándares técnicos del contrato, señalando nuevamente el imperativo de velar por la sostenibilidad financiera de la modificación con relación a Desarrollo País.

En lo que atañe a otras modalidades de contratación, la Ley no entrega mayor detalle sobre el asunto, lo que creemos también podría considerarse como una imprecisión de la norma. Esto, pues, considerando que el equilibrio financiero-económico del contrato es un elemento fundamental para el correcto desarrollo del proyecto en todas sus etapas, debiera por necesidad hacerse un reconocimiento expreso de este, ya sea en las bases de licitación o algún otro documento que formen parte del contrato, si es que no se incorporase en una reforma legal futura para explicitarlo.

24 En cualquier caso, independiente de la modalidad, deben respetarse los principios de competencia, estricta sujeción a las bases e igualdad entre los oferentes, así como la transparencia, como señala el inciso primero. Además, debe cumplirse con las disposiciones sobre probidad contenidas en el artículo 4 inciso sexto de la Ley I9.886.

25 Se excluyen los artículos 8; 9; I9, inciso final; 20; 20 bis; 2I; 25, y 39, así como las normas reglamentarias que se deriven de estas disposiciones. 
Cabe señalar que la Ley entrega la posibilidad de transferir el derecho de concesión, en la medida en que el cesionario reúna ciertos requisitos establecidos en la ley, las bases de licitación y otros instrumentos que formen parte del contrato. ${ }^{26}$ Este derecho y las obligaciones correlativas deben cederse como un todo y la operación deberá ser autorizada por el Fondo, quien también deberá aprobar cualquier tipo de enajenación cuyo porcentaje sea superior al $15 \%$ de las acciones de la sociedad concesionaria (según el artículo 8 de la Ley).

Por último, al Fondo, además de regirse por la Ley 21.082, le serán aplicables las normas de las sociedades anónimas abiertas, es decir, la Ley 18.046, sobre Sociedades Anónimas, y las demás aplicables a ese régimen jurídico, además de las propias de empresas públicas, como son las atribuciones que al respecto tiene la Dirección de Presupuestos, entre otras.

\section{7. ¿Por qué se crea una empresa pública para desempeñar funciones que históricamente le han correspondido al Ministerio de Obras Públicas?}

Más allá de las ya expuestas razones históricas que llevaron a crear esta empresa, resulta importante explorar qué ventajas tiene esta figura por sobre mantener la construcción de infraestructura pública principalmente en el Ministerio de Obras Públicas.

Entendemos que la principal ventaja de constituir el Fondo como una empresa del Estado es la de retener y asegurar el uso del valor residual de la infraestructura pública concesionada para la generación de infraestructura nueva, pues, de otro modo, estos recursos pasarían a formar parte del presupuesto público y, por tanto, podrían ser asignados a otras tareas fiscales que también demandan recursos con urgencia. Por lo anterior, la creación del Fondo se encuentra ligada a la voluntad política de reservar los recursos públicos provenientes del sector de la infraestructura (conocido como earmarking o ring-fencing), para que sean utilizados en dicho mercado, garantizando con ello la disponibilidad de recursos en el tiempo para aumentar la inversión tanto pública como privada.

Al tratarse de una empresa autónoma, con capital propio y un gobierno corporativo independiente de la Administración del Estado, Desarrollo País permitiría, mediante el mecanismo de deuda, trasladar ingresos futuros al presente para adelantar la disponibilidad de recursos fiscales, con el objeto de invertir en proyectos de infraestructura. Esto, ya que dicho adelanto de recursos no será contabilizado ni tratado como una deuda pública. ${ }^{27}$

26 La Ley ha establecido una acción de nulidad de pleno derecho en contra de aquellas transferencias que no cumplan con los requisitos establecidos en su artículo 7 .

27 En Chile, la regla fiscal de balance estructural considera como gastos del Estado aquellos hechos por el Gobierno central, lo que incluye ministerios, otros poderes del Estado y servicios públicos descentralizados. Quedan fuera de la regla las empresas públicas, municipalidades y universidades estatales. 
De este modo, los gastos ejecutados a través del Fondo, así como las obligaciones contraídas con ciertos acreedores, no pasarán a formar parte del presupuesto público. Esto le otorga mayor libertad para ejecutar una agenda de inversión en infraestructura con mirada a largo plazo, mediante planes quinquenales, sin estar sometido a presiones ni contingencias políticas.

Por su parte, es una empresa que tiene objetivos definidos de manera muy específica; como ya se ha señalado, el Fondo deberá orientarse a la sostenibilidad financiera de su cartera de proyectos y a producir utilidades cada año. En ese sentido, la regulación de los gobiernos de las sociedades anónimas y las empresas que emiten deuda son especialmente estrictas, en especial para supervisar que los directores cumplan el objetivo de proteger los intereses de la empresa. Por tanto, si las gestiones de los directores se alejan de dicho objetivo, estos podrían responder incluso con su patrimonio personal.

En síntesis, las empresas públicas poseen mayor independencia y autonomía respecto del Gobierno central; y si bien es el presidente quien designa a los directores, estos últimos no pueden ser removidos por la mera voluntad de la autoridad política. A su vez, comparadas con una institución de la Administración, las empresas públicas cuentan con mayor flexibilidad a la hora de contratar personas, obras y servicios, así como la facultad de gestionar su propio patrimonio, lo que le otorga ventajas a la hora de ejecutar los objetivos por la cual fue creada.

\section{8. ¿Por qué se fijó un giro tan amplio para el Fondo?}

El Fondo cuenta con un giro amplio en comparación con la mayoría de los que en la actualidad operan en el mundo, pues estos suelen restringir su actuar al ámbito financiero de los proyectos, es decir, son principalmente organismos que otorgan créditos. En el caso de Chile, el Fondo puede gestionar servicios de infraestructura mediante terceros no relacionados, lo que resulta curioso, ya que se trata de una atribución que corresponde más a las labores de una agencias o dirección de obras concesionadas que a las de un fondo de inversión. ¿Por qué nos encontramos frente a esta situación?

No pudimos encontrar con claridad en la historia de la ley cuál fue el motivo de esta relativa innovación, que en nuestra opinión introduce el riesgo de difuminar el foco de Desarrollo País dentro del sistema de generación de infraestructura pública, operando en áreas o negocios ya cubiertos por otras instituciones del Estado o actores del mundo privado. ${ }^{28}$

28 Esto fue criticado en su oportunidad por el Consejo de Políticas de Infraestructura: C. Pérez y Cueto V., «CPI: Fondo de Infraestructura podría afectar libre competencia», La Tercera, 20 de noviembre de 20I7, https://www.latercera.com/noticia/cpi-fondo-infraestructura-podria-afectar-libre-competencia/. 
Consideramos que dicha facultad se encuentra en tensión con el principio de subsidiariedad, consagrado en el artículo 19, numeral 21. ${ }^{\circ}$, inciso segundo de la Constitución, y el de autonomía de los grupos sociales intermedios, contemplado en el artículo 1, inciso tercero, así como en el artículo 3 de la Ley 18.575, Orgánica Constitucional de Bases de la Administración del Estado. ${ }^{29}$ Por tanto, resulta de vital importancia evaluar si la actividad privada está cumpliendo en forma adecuada con estos fines, como veremos más adelante al analizar los posibles proyectos de infraestructura concesionada en los que podría participar el Fondo.

Ahora bien, dada la restricción asociada a la directriz de no generar pasivos fiscales, no se puede separar la función desarrolladora de la financista, en especial si se considera que el Fondo solo puede invertir, conservar y explotar proyectos de infraestructura a través de terceros. Por lo tanto, es posible que el Fondo ejerza primordialmente un rol financista, otorgando garantías de ingresos a las concesiones de obras públicas más riesgosas, o bien, como prestamista tradicional en proyectos del ámbito de empresas estatales del sector de infraestructura.

En ese orden, el Fondo va a entregar garantías de ingresos mínimos a los proyectos de concesiones, reemplazando con ello la función que en la actualidad ejerce el MOP. A su vez, va a participar en la financiación de proyectos de largo plazo, los cuales muchas veces no son rentables privadamente dentro de los periodos promedio de una concesión. El Fondo otorga entonces un subsidio al concesionario y recupera el valor económico residual del proyecto al final del periodo de concesión cuando reciba la obra para su relicitación.

\section{9· ¿Qué tipo de proyectos debiera financiar el Fondo?}

Como ya fue señalado, la exigencia de que los nuevos proyectos del Fondo tengan que generar utilidades impone una restricción sobre el tipo de concesiones que este podrá financiar, ya que solo aquellos proyectos que durante su vida útil generen utilidades netas positivas podrían ser financiados, según su mandato legal.

A la fecha, Desarrollo País no ha iniciado ningún proyecto; no obstante, consideramos que existen tres tipos que podría financiar:

- Proyectos rentables privadamente, que generan utilidades durante el periodo de concesión, sin necesidad de subsidios. Es de toda lógica suponer que este tipo de proyectos no va a requerir de la colaboración del Fondo para su eje-

29 Bajo ambos principios, así como el Estado debe propender a alcanzar el bien común como función principal, así también debe abstenerse de desplazar a los particulares o cuerpos intermedios en la consecución de sus iniciativas propias. 
cución, pues no es necesario un subsidio para el plazo de operación definido y pueden desarrollarse mediante el mecanismo tradicional. No debiera ser difícil obtener la totalidad del financiamiento necesario para desarrollar el proyecto desde el mundo privado.

- Proyectos que generan valor privado al Fondo pero requieren de subsidios para su ejecución, dado el plazo de concesión definido en las bases de licitación. Estos serían proyectos que generan valor en el largo plazo y que no resultan muchas veces rentables para el privado, principalmente por los tiempos de retorno de la inversión.

- Proyectos socialmente rentables pero que no generan valor al Fondo, y que solo podrían concretarse mediante este mecanismo si el Estado entrega un subsidio.

Es del todo razonable suponer que el aporte de Desarrollo País, como instrumento de inversión, va a resultar más relevante en el caso intermedio, es decir, en aquellos proyectos en los que se produce un valor en el largo plazo y que necesariamente requieren de un subsidio para ser materializados dentro del plazo de la concesión. Como se explicó, en este caso el Fondo otorga un subsidio al concesionario y recupera el valor económico residual del proyecto al final del periodo de concesión, cuando reciba la obra para su relicitación.

Cuando existen proyectos rentables privadamente dentro del periodo de la concesión y proyectos rentables socialmente pero no en términos de su valor, incluso en el largo plazo, el Fondo también podría participar, siempre y cuando reciba un subsidio del Fisco para ello; sin embargo, no representa ventaja en comparación con el mecanismo actual empleado por el MOP, salvo, tal vez, en cuanto existiría una mayor disponibilidad de recursos.

\subsection{0. ¿Podría el Fondo financiar o invertir en proyectos rentables socialmente pero no rentables privadamente? ${ }_{3}$ Son posibles los subsidios cruzados entre distintos proyectos?}

Como ya fue señalado, el artículo 4 de la Ley obliga al Fondo a orientarse a la sostenibilidad financiera de su cartera de proyectos y a producir utilidades anuales durante cada ejercicio. Es decir, la sostenibilidad financiera con que debe cumplir se mide a partir de su cartera de proyectos anual y no de cada proyecto en particular. Por tanto, en nuestra opinión existe un espacio para que dentro de una misma cartera puedan convivir proyectos rentables privadamente y otros no rentables pero sí socialmente deseables, siempre y cuando cada año la cartera arroje una rentabilidad económica positiva. Es decir, en determinadas ocasiones, Desarrollo País podrá hacerse cargo de un proyecto cuyo flujo de ingresos no cubra por completo sus costos. ${ }^{30}$

30 Este suele ser el caso, por ejemplo, de la infraestructura ferroviaria. 
Además, en caso de que sea la Administración la que requiera al Fondo llevar a cabo obras o proyectos que le provoquen un impacto negativo, la regulación, con el objeto de no deteriorar el patrimonio de la empresa y cumplir con el mandato de la Ley, se dispone en el artículo 23 que Desarrollo País puede recibir capitales desde la Ley de Presupuestos del Sector Público. Cabe precisar que se trata de transferencias específicas y relacionadas con proyectos en particular, no con el funcionamiento ordinario de la empresa.

Ahora bien, debido a que el Fondo está llamado a ser un garante de la neutralidad competitiva en el mercado de la infraestructura pública, y como veremos más adelante, debe ser cuidadoso de no favorecer un funcionamiento ineficiente en el mercado, o de introducir distorsiones en este a través de su actuar, al ser una empresa pública. Ello es algo que tendrá que ir analizando caso a caso para cada proyecto, teniendo siempre a la vista que se encuentra sujeto a las normas del Decreto Ley 211 de $1973,{ }^{31}$ por disponer la Constitución que dichas empresas se rigen por el régimen común aplicable a los particulares.

\section{II. ¿Quién fiscaliza el correcto funcionamiento del Fondo?}

Es importante para el buen funcionamiento de esta empresa que cuente con sistemas de fiscalización y corrección, considerando, en especial, que toda empresa pública debe tener siempre en vistas el interés común.

En primer lugar, y como fue señalado, el artículo 25 establece que el directorio del Fondo deberá presentar anualmente un plan de negocios quinquenal, el cual será aprobado por la junta de accionistas. Este plan deberá contener los objetivos y metas de rentabilidad, los planes de inversión y los proyectos de infraestructura a desarrollar. Además, contará con la supervisión del MOP, que elabora un informe técnico calificando su contenido. Por tanto, es fiscalizado directamente por su propia junta de accionistas e indirectamente por el MOP.

En segundo lugar, aquellos proyectos de Desarrollo País que requieran aportes fiscales para su ejecución deben contar con la autorización del Ministerio de Hacienda, así como la evaluación del Ministerio de Desarrollo Social y Familia.

En tercer lugar, al ser aplicables al Fondo las normas de las sociedades anónimas abiertas, este quedará sujeto a la fiscalización de la Comisión para el Mercado Financiero. ${ }^{32}$ Por lo

31 Diego Pardow y Rodrigo Vallejo, «Derribando mitos sobre el Estado empresario», Revista Chilena de Derecho 35, n. $^{\circ}$ I (20I8): $\mathrm{I}_{3} 5^{-\mathrm{I}} 5^{6}$.

32 Artículo 29. Además, de acuerdo con la Ley 20.285, sobre Acceso a la Información Pública, todas las empresas públicas están obligadas a entregar a la CMF, o a la Superintendencia a cuya focalización se encuentren sometidas, la misma información que se les pide a las sociedades anónimas abiertas en la Ley de Sociedades Anónimas. 
anterior, debiera ser aplicable al Fondo la regla de fiscalización interna de las sociedades anónimas abiertas - obligación de designar anualmente una empresa auditora externacontenida en el artículo 52 de la Ley de Sociedades Anónimas.

En cuarto lugar, la Contraloría General de la República ejercerá su función fiscalizadora, cautelando «el cumplimiento de los fines de estas empresas, sociedades o entidades» (artículo 16, inciso segundo de la Ley 10.336). ${ }^{33}$ Además, al ser esta una empresa pública en que el Fisco tiene más de $50 \%$ de participación, se sujeta a reglas de transparencia de la Ley 20.285, lo que permite que la ciudadanía en general conozca sus estados financieros, remuneraciones, etcétera.

Por último, respecto de los límites en el endeudamiento, no existe a priori en la ley un límite establecido, posiblemente porque se espera que sea el propio mercado el que lleve a cabo esta tarea, dado el patrimonio de la empresa y su capacidad de generar ingresos. De todos modos, sabemos ya que para velar por la responsabilidad fiscal del Fondo se ha establecido que, como sociedad anónima, debe ser solvente. Esto se traduce en que el Fondo deberá orientarse a la sostenibilidad financiera de su cartera de proyectos y a producir utilidades anuales y, por otra parte, que los recursos o transferencias que requieran del Fisco se orienten a proyectos que no disminuyan el patrimonio de la empresa.

\subsection{2. ¿Qué ocurre con la naturaleza jurídica de las tarifas que hoy pagan los usuarios?}

En esta sección se detallará una de las dudas que existen en el funcionamiento del Fondo. En específico, respecto de la posibilidad de que una obra construida por Desarrollo País bajo el modelo de concesión sea tarificada, y, en ese caso, cuál es el régimen de esas tarifas o peajes.

Tal como ha sido reiterado en la jurisprudencia, los peajes o tarifas que pagan los usuarios por el uso de obras públicas concesionadas son un tipo de carga pública. Como sabemos, la potestad tributaria del Estado proviene de sus objetivos de servicio a las personas y promoción del bien común, pues requiere obtener los recursos necesarios para cumplirlos. ${ }^{34}$ Los peajes o tarifas han sido definidos como «la remuneración o contraprestación exigible al usuario o beneficiario de un servicio público otorgado directa o indirectamente por una Administración, que será de distinta naturaleza según el modo de gestión de dicho

33 En este punto, tiene especial interés la doctrina del «núcleo público», que la Contraloría General de la República ha venido desarrollando en diversos dictámenes, entre ellos, el Dictamen I2.059/20II; Dictamen I2.37I/20I4, y Dictamen 49.I35/20I5.

34 Teodoro Ribera, «La potestad tributaria del Estado», Revista de Derecho Público 62 (2000): 24 . 
servicio»; ${ }^{35}$ entonces, la tarifa deriva de la existencia de un servicio público, calificado como tal por la autoridad, como remuneración. ${ }^{36}$

El Tribunal Constitucional, en sentencia rol 183 de 1994, confirmó que los peajes son tributos - según el artículo 19, numeral vigésimo de la Constitución— que, en el caso estudiado, afectaban la construcción y mantención de la red caminera del país. Ello claramente es independiente de que exista un contrato entre la Administración y el concesionario, puesto que la naturaleza de la obra encargada es pública; es decir, aun cuando la tarifa se destina al pago de la inversión realizada por el adjudicatario del contrato, sigue siendo una carga pública.

Esto se ve refrendado por la regulación específica del MOP. Así, el artículo 75 de la Ley 15.840, Orgánica del Ministerio de Obras, le confiere al presidente de la República la facultad de establecer peajes en los caminos, puentes y túneles que estime convenientes, además de fijar su monto, mientras que puede eximir a algunos vehículos de dicho pago. Luego, el artículo 1 bis, letra h) de la Ley de Concesiones establece una Política Nacional de Peajes, a cargo del MOP, que será aplicable a todas las rutas y carreteras amparadas por esta ley. Por otra parte, el artículo 11 de la misma ley establece que la compensación por las obras que realice el concesionario será una tarifa, precio o subsidio que se establecerá el proceso de licitación correspondiente. Estas normas no fueron modificadas a propósito de la creación del Fondo. Por tanto, se puede observar que las obras que se concesionen por parte de Desarrollo País estarán sujetas, en lo pertinente a las concesiones de infraestructura vial, a estas regulaciones de peajes o tarifas.

Sin embargó, como se señaló más arriba, existen dudas respecto del patrimonio del Fondo, que según el artículo 11 de la Ley 21.082 estará en parte constituido por aporte de bienes fiscales y bienes nacionales de uso público. Entonces, si los peajes son tributos que afectan una obra pública, y esta se construye en un bien que fue traspasado en propiedad a una empresa pública, ¿siguen siendo tributos?

Pues bien, y como ya fue explicado, creemos que, primero, es imposible enajenar un bien nacional de uso público, y por tanto solo podría traspasarse su administración. Segundo, los bienes fiscales, aun cuando podrían ser traspasados, entendemos que se harían bajo la condición de continuar con el uso de estos en pos del bien común. Por tanto, al no modificarse el estatuto de las concesiones de obra pública, y considerando la finalidad

35 Patricio Masbernat, «Retorno al debate conceptual de tasa y tarifa como un parámetro de los límites del concepto de tributo: Comentario a la sentencia del Tribunal Supremo de España 5०37/20I5, de 23 de noviembre de 20I5, recaído en recurso de casación 409I/20I3», Revista Chilena de Derecho $44, \mathrm{n} .^{\mathrm{o}}{ }_{3}(20 \mathrm{I} 7)$.

36 Masbernat, «Retorno...». 
de los tributos y cargas públicas contemplado en el artículo 19 numeral vigésimo de la Constitución, consideramos que la naturaleza jurídica de las tarifas no se ve modificada en el caso de las concesiones que realizará el Fondo.

Por último, se observa una contradicción entre las normas expuestas en esta sección y el artículo 5 de la Ley 21.082, que contempla las formas en que el Fondo puede otorgar concesiones a terceros. Como ya se señaló, para ello se utilizará el estatuto jurídico de concesiones contenido en el Decreto Fuerza Ley 164 de 1991, Ley de Concesiones, pero solo le serán aplicables las normas contenidas en los capítulos 3 a 11 de dicha ley. Este es otro aspecto que, a nuestra consideración, no fue correctamente redactado en la norma.

Esto presenta el inconveniente de que la regulación respecto de la Política Nacional de Peajes se encuentra en el capítulo 1 de dicha ley; y, por tanto, se daría una situación en la cual los peajes de las concesiones que otorgue Desarrollo País quedarían fuera de dicha política, cuestión que claramente es problemática. Es posible que aquello se deba a un error en el proceso legislativo, que de todas formas es de fácil solución, pues basta con incluir el artículo 1 bis de la Ley de Concesiones dentro del marco de funcionamiento del Fondo, o bien, puede incluirse dicha norma dentro de las bases de licitación de cada proyecto.

\section{POSIBLES RIESGOS ASOCIADOS A LA INTRODUCCIÓN DEL FONDO AL SISTEMA DE INFRAESTRUCTURA}

Teniendo en consideración todo lo recién expuesto, creemos que este nuevo actor en el sistema de infraestructura chileno, una vez comience a ejecutar proyectos, puede generar una serie de riesgos que es importante tener presente en la redacción de bases de licitación y los respectivos contratos, así como también considerarlos a la hora de evaluar posibles reformas legales o reglamentarias:

Crowding out. Este efecto se entiende, en general, como la disminución de la disponibilidad de crédito para el sector privado como consecuencia de la mayor participación del Gobierno en el crédito interno. ${ }^{37}$ Creemos que este efecto pueden presentarse una vez que el Fondo empiece a operar en capacidad, pues se puede desincentivar los préstamos desde la banca o entidades privadas a los actores que ejecutan estos contratos, principalmente porque, ante los particulares, se generaría una fuente de crédito más barata y menos riesgosa en el tiempo. Por tanto, podría crear un perjuicio para los actores privados en el mercado crediticio, relacionado con la construcción de infraestructura, disminuyendo de este modo la disponibilidad de esa oferta.

37 Luis Molina, «El crowding out o efecto de expulsión», Revista Universidad EAFIT $3^{2,}$ n. ${ }^{\circ}$ I०3 (I996): 67 . 
Calidad de los proyectos. Otro riesgo que puede presentarse, pero que es uno inherente al sistema de concesiones de obra pública en general - no solo cuando sean llevados a cabo por Desarrollo País-, es que cuando el Estado garantiza ciertos proyectos, se puede producir un incentivo perverso respecto de la calidad de sus proyectos y el cumplimiento de los niveles de servicio, ya que de todas formas los retornos mínimos estarán asegurados para el contratista. Además, hay autores que apuntan a que la reducción de costos de explotación por parte de la industria privada podría verse traducida en la prestación de servicios de menor calidad, en especial en obras en que el privado es quien provee un servicio público, como podría ser el caso de los hospitales. ${ }^{38}$ Ello también puede significar una mayor presión para los inspectores fiscales ${ }^{39}$ en su labor de seguimiento del contrato, ya que eventualmente tendrán que cumplir una labor más demandante y acuciosa, si es que llegasen a percatarse de la existencia de este incentivo perverso. Considerando lo complicada que suele ser esta labor, imponer más presión sobre ella puede traer consecuencias negativas sobre el desempeño en la fiscalización de la correcta ejecución de las obras y la posterior explotación.

Conflictos de interés. Al ser Desarrollo País prestamista-inversor y al mismo tiempo contraparte de los proyectos, se pueden generar conflictos de intereses en el desarrollo de los proyectos que ejecute, en especial respecto de los posibles reclamos de parte del contratista. En el sistema tradicional esto no ocurre, puesto que el MOP no interviene en el área de financiamiento de los proyectos - solo exigirá una cierta capacidad financiera-, sino que ello es responsabilidad exclusiva de los licitantes y contratistas; luego, de existir reclamos de carácter financiero, el MOP y el contratista no tendrán relación entre sí. Sin embargo, esto no ocurriría en el caso de Desarrollo País, lo que podría verse agudizado en aquellos proyectos que pueden resultar difícilmente financiables por privados, en que el Fondo tendrá la posición de ser la única alternativa existente para ejecutar la infraestructura.

Poder de mercado. Se debe tener presente que los grandes proyectos de infraestructura normalmente confieren un alto poder de mercado, debido a la ausencia de sustitutos equivalentes. Este poder implicaría que el actor podrá mantener durante un periodo de tiempo significativo precios superiores a los niveles que permitiría un escenario competitivo. ${ }^{40}$ Por consiguiente, un riesgo asociado a este poder es que el Fondo podría con facilidad

38 Martín Loo, «El desafío de las concesiones de obra pública: ¿Qué (y qué no) concesionar?», Revista de Derecho (Valdivia) $3^{2,}$ n. ${ }_{2}$ (2019): 194.

39 Estos son los funcionarios públicos a los cuales la Ley de Concesiones les entrega el rol de fiscalización de cumplimiento del contrato de concesión, tanto en la etapa de construcción como de explotación de la obra.

40 Rubén Bahamonde, «El poder de mercado y su relevancia en el derecho de la competencia europeo», Anuario da Facultade de Dereito da Universidade da Coruña I7 (2013): 488. 
aumentar sus ingresos mediante el alza de los cobros a los usuarios. Otra vez, esto es un riesgo inherente a esta clase de obras, solo que se introduce un nuevo actor que podría utilizar ese poder. En virtud de ello, creemos que es necesario que exista un contrapeso externo que supervise la política de cobros a usuarios definida por el Fondo, ya que la versión actual de la ley no señala sobre quién recae esta responsabilidad. Lo mismo aplica para el riesgo inverso, es decir, que existan presiones para reducir las tarifas o eliminarlas, en especial cuando un nuevo concesionario únicamente asuma el costo de la operación y mantenimiento de la infraestructura, sin obras adicionales.

En cuanto a las garantías, consideramos que también existen riesgos, ya que el capital del Fondo, al basarse en los flujos futuros, puede generar una presión en adelante para lograr materializar dichos flujos esperados, condicionando desde un comienzo los parámetros de licitaciones futuras. Una manera de mitigar dicho riesgo es que el Fondo ejecute obras en la medida en que se vayan materializando dichos flujos futuros.

\section{CONCLUSIONES}

En 2018, mediante la Ley 21.082, se creó una nueva empresa pública, llamada Fondo de Infraestructura en Chile S. A., con la idea de permitir el traspaso de flujos financieros que generan algunos activos del sistema de concesiones a otros proyectos de infraestructura pública, a fin de aumentar la capacidad del país para desarrollar dichas obras.

Al tratarse de una empresa autónoma, con capital propio y un gobierno corporativo independiente de la Administración del Estado, la principal ventaja de Desarrollo País es que, mediante el mecanismo de deuda, se trasladen ingresos futuros al presente, adelantando la disponibilidad de recursos fiscales con el objeto de invertir en proyectos de infraestructura, en vez de que estos se utilicen en otras tareas.

Según lo dispuso dicha Ley, el Fondo - hoy denominado Desarrollo País-, a diferencia de la mayoría de los existentes a nivel mundial, además de administrar instrumentos financieros asociados a proyectos de infraestructura, también tiene asignadas tareas respecto de la construcción, ampliación, reparación, conservación, explotación y desarrollo de proyectos de infraestructura, sea por sí o a través del MOP, orientándose a la sostenibilidad financiera de su cartera de proyectos y a producir utilidades cada año. No cuenta con restricciones para la naturaleza de los proyectos, por lo que podrían ser de diversos tipos, como autopistas, comunicaciones, obras de urbanismo, etcétera.

Ahora bien, el Fondo, aunque ha sido constituido, todavía no ha llevado a cabo ninguna obra, por lo que no hay seguridad sobre su funcionamiento e impacto en el sistema de infraestructura en Chile. Si bien se trata de una iniciativa interesante, que puede traer muchos beneficios para la reactivación del mercado de la infraestructura pública en el 
país, existen aún interrogantes respecto de la operación de esta empresa pública, así como de la normativa que le dio vida, que en varios aspectos necesita de un mayor desarrollo y precisión.

En definitiva, podemos resumir los principales problemas que identificamos en este trabajo del siguiente modo:

Primero, no existe claridad respecto de la composición del capital del Fondo, ya que por una parte la Ley señala que el Fisco podrá suscribir y pagar el capital inicial, total o parcialmente con el aporte de bienes fiscales y nacionales de uso público, a pesar de que es jurídicamente insostenible que se aporten bienes nacionales de uso público. Aun cuando esto todavía no ocurre en la práctica, estimamos que es algo que debe aclararse para señalar que se entregarán no en propiedad, sino que para su administración.

Segundo, el Fondo puede gestionar servicios de infraestructura mediante terceros no relacionados, lo que resulta curioso, pues podría llevar a esta empresa pública a entrometerse en áreas en que actores públicos o privados ya se encuentran operando, además de ser un posible foco de contradicción con la garantía del artículo 19 numeral 21. ${ }^{\circ}$ de la Constitución Política.

Tercero, respecto a su cartera de proyectos, creemos que pueden convivir proyectos rentables privadamente y otros que sean rentables socialmente, aunque no económicamente, pero siempre que esta arroje una rentabilidad económica positiva. En este sentido, además, deberá velar el Fondo en cumplir con las normas de libre competencia, analizando caso a caso si su actuar puede generar distorsiones en el mercado. Evaluamos en forma positiva la línea de proyectos que Desarrollo País ha declarado como prioritarios, como edificaciones para arriendos subsidiados, plantas desaladoras y otro tipo de infraestructura de relevancia social.

Cuarto, también creemos que, al no alterar esta ley el estatuto de las concesiones de obra pública, y teniendo en consideración la jurisprudencia del Tribunal Constitucional respecto de la naturaleza jurídica de los peajes o tarifas, las posibles obras concesionadas por el Fondo no modificarán dicha naturaleza, por lo que serán entonces cargas públicas en los términos indicados en el artículo 19 numeral vigésimo de la Constitución. Ahora bien, la ley actual presenta una contradicción, al excluir estas obras de la Política Nacional de Peajes, lo que creemos se trató de un mero error en el trámite legislativo, que puede ser enmendado en una futura modificación a la Ley 21.082 o en los contratos de licitación.

Por último, prevemos una serie de riesgos asociados a la introducción de este nuevo actor al sistema de infraestructura chileno. Por una parte, está el riesgo de crowding-out en cuanto a desincentivar a los actores privados del mercado de financiamiento para entregar capital a este tipo de proyectos. Luego, existen riesgos propios de los sistemas de obras 
públicas que podrían verse magnificados por la introducción de este nuevo actor, como la presencia de incentivos perversos en el nivel de calidad de los proyectos y el poder de mercado que entregan. Además, se presenta un posible conflicto de interés para Desarrollo País, por su rol doble de financista y mandante de los proyectos. Estos riesgos deberán tenerse en cuenta una vez se encuentre actuando e interviniendo en el mercado, a fin de mitigarlos y, de ser imperioso, introducir cambios en la regulación que resulten necesarios.

\section{RECONOCIMIENTO}

Este documento forma parte de una investigación personal de los autores. 


\section{BIBLIOGRAFÍA}

- Bahamonde, Rubén. «El poder de mercado y su relevancia en el derecho de la competencia europeo». Anuario da Facultade de Dereito da Universidade da Coruña 17 (2013): 487-499.

- De la Cruz, Alicia. «Fondo de infraestructura: Las dudas frente a inconsistencias de derecho público». Cuadernos de Extensión Jurídica de la Universidad de los Andes 31 (2018): 135-143.

- González, Aldo. «El fondo de infraestructura de Chile». Estudios de Políticas Públicas 4, n. ${ }^{\circ} 2$ (2018): 174-186. https://doi.org/10.5354/0719$\underline{6296.2018 .51728}$

- Loo, Martín. «El desafío de las concesiones de obra pública: ¿Qué (y qué no) concesionar?». Revista de Derecho (Valdivia) 32, n. ${ }^{\circ} 2$ (2019): 185-206. https://doi.org/10.4067/S0718-09502019000200185

- Masbernat, Patricio. «Retorno al debate conceptual de tasa y tarifa como un parámetro de los límites del concepto de tributo: Comentario a la sentencia del Tribunal Supremo de España 5037/2015, de 23 de noviembre de 2015, recaído en recurso de casación 4091/2013». Revista Chilena de Derecho 44, n. ${ }^{\circ} 3$ (2017): 865-884. doi: 10.4067/S071834372017000300865 .

- Molina, Luis. «El crowding out o efecto de expulsión». Revista Universidad EAFIT 32, n. ${ }^{\circ} 103$ (1996): 67-75.

- Pardow, Diego y Rodrigo Vallejo. «Derribando mitos sobre el Estado empresario». Revista Chilena de Derecho 35, n. ${ }^{\circ} 1$ (2008): 135-156. https://doi.org/10.4067/S0718-34372008000100006

- Ribera, Teodoro. «La potestad tributaria del Estado». Revista de Derecho Público 62 (2000): 22-31. https://doi.org/10.5354/0719$\underline{5249.2016 .43193}$ 